\title{
Fostering Ethical Behavior and Culture in Nigeria Schools
}

\author{
Lekia Nwikina, PHD \\ Department of Educational Management, \\ University of Port Harcourt, Rivers state, Nigeria
}

Doi:10.5296/ijld.v3i6.4706 URL: http://dx.doi.org/10.5296/ijld.v3i6.4706

\begin{abstract}
The paper highlights the range of ethical behaviour problems of school personnel that frequently confront educational leaders. It seeks to highlight and proffer solutions to problems associated with lack of trust, lack of proper value orientation; lack of integrity and responsibility in, and of school organization. It also seeks to recommend measures for building and sustaining school corporate ethics and values. Ethics and relevant moral values should be transmitted, promoted and protected as the school corporate culture by words of mouth indoctrination and power of tradition, and by setting forth a code of ethics and values in written document. Once set forth, they should be ingrained in the school policies, practices and actual conduct; they should not be window dressing or just a show. Values and code of ethics should be implemented by incorporating the statement into staff and students' training and educational programmes; giving explicit attention to values and ethics in recruiting and hiring or screening out applicants who lack compatible character traits, communication of values and ethics code to all employees and students and explaining compliance procedures. Most important of all is strong leadership commitment and endorsement of excellent ethical examples in their own behavior - Principal must be able to reprimand those who have been laxed in monitoring and enforcing ethical compliance and must not hesitate to remove, or recommend removal of people who are guilty of violation. When successful implemented, ethics improves the organisation's survival prospects, enhances its mission achievement opportunities and its reputation.
\end{abstract}

\section{Introduction}

The National Policy on Education (FRN, 2004) has very high promises for promoting Nigeria national ethics of discipline, integrity, dignity of labour, social justice, religious tolerance, self respect and patriotism. It emphasizes respect for the worth and dignity of the individuals, faith in man's ability to make rational decisions; moral and spiritual principles in interpersonal and human relation; shared responsibility for the common good of society; promotion of the physical, emotional and psychological development of all children; and acquisition of competences necessary for self- reliance. It appears however, that ethical behaviors including trust, appropriate social and moral values, integrity and responsibilities are deeply eroding from Nigeria education. Many researchers (Mni, 2008) think that the general perception of many Nigerians is that our national values as portrayed by our schools, have drifted to unacceptable standards since several decades - with corruption in high places, distortion of justice and high waves of indiscipline, dishonesty, cheating, lying, and administrative malpractice and other vices.

The term "ethics" means the system of rules that governs the ordering of values (Bateman and Snell, 1999), or as Siropolis (1997:62) puts it "the rules or standards governing the conduct of a person or a profession", and "ethical", the behavior that live up to the standards set by the 
society; while "unethical" means the wrong behavior (that) does not "(live up to the standards set by the society). Siropolis, further indicates that there are three kinds of wrong behavior:

$>$ Violation of law. Examples; paying or receiving a bribe; and illegally levying students.

$>$ Departure from truth. Examples; saying anything that does not fit the fact- calling in sick when you are not.

$>$ Deviation from moral rectitude. Examples; cancelling a meeting with employee without bothering to call him back. Passing off as your own idea a new product which infact somebody else has proposed first. Also teachers or students lacking responsibility to his own action or inaction and thus, shifting blame are other examples. Deviations from moral rectitude are wrong not because they dodge the fact or break the law but rather because they go against our moral fiber.

The concepts of "trust"; responsibility" and integrity" are part of the value system of excellent school management. Ethical behavior builds on trust, and trust is essential ingredient of quality management: various elements of quality management depend on trust, communication, interpersonal relations, conflict management, problem solving, teamwork, employee involvement, employment, and custom focus. This means that the excellent education proposed by the National Policy on Education can not be successfully implemented without sound ethical behavior of the stakeholders.

Much of the litigations, disturbances, lose of jobs and wastages in the education subsector has also been shown to be associated with ethical issues (Igwe, 2003, Amirize, 2005). It is important therefore to study the subject "ethics", since as Zietlow (2004:1230) says, "its implementation improves the organisation's survival prospects, enhances its missions achievement opportunities and build the organisation's reputation."

The purpose of this paper is to highlight the range of the most frequently reported ethical behavior problems in Nigeria schools; the solutions toward building trust; solutions that best fit school value system; solutions that enhances the school organizational integrity; solution for promoting responsibility, and solutions for entrenching ethical culture in the school organizations.

\section{Range of Unethical Behaviours that Frequently Confront Educational Leaders}

Ethical behavior problems in Nigeria education may be classified as shown above; namely violation of law, departure from the truth, and deviation from moral rectitude. They may also be classified in respect of those associated with lack of trust; lack of accountability or responsibility to one's duty action or inaction; lack of integrity, and poor value system (as the case of school- age children whose preference is getting rich now to getting education). They are also classified in respect of those expectations from lecturers, non- teaching staff and those from students. The sources of ethical problems listed below are Fayokun and Adedeji (2008), University of Port Harcourt code of conduct, and Rivers State Government (RSG, 2009).

1. Lateness to school and school assemblies

2. Interval absenteeism from school

3. Lateness to the classroom for teaching

4. Failure to prepare lesson notes

5. Failure to attend staff meetings

6. Examination malpractices (aiding or abetting)

7. Failure to make use of the blackboard for teaching

8. Indulging in behaviours that tend to degrade the personality of a student (eg. Hair cutting as punishment or cutting skirt to size) or of a teacher.

9. Failure to perform duty (as house or duty master- not keeping appropriate house/duty records).

10. Indecent dressing 
11. Contributing to delinquency of a minor

12. Deliberate negligence of duty

13. Beating or punishing students in disregard to rules and regulations for punishment.

14. Stealing of school property (eg. Stencils, stationery, typewriters, stop watches, microscope)

15. Fighting with colleague or student

16. Rudeness or insubordination to the principal or his representative

17. Corruption or fraudulent practices, eg. Collecting illegal dues from students, embezzlement of school fees etc

18. Failure to keep records of tests and examination

19. Failure to mark class register - as class teacher

20. Aiding students in destabilizing the peace and unity of the school

21. Forgery of certificates and other personal documents; giving false information

22. Engaging in activities or crimes that will jeopardize or bring disrepute to the teaching profession or to the school

23. Drinking alcohol while on duty or getting intoxicated to school

24. Sleeping while on duty

25. Smoking while on duty, particularly while teaching

26. Leaking official and confidential documents to unauthorized persons

27. Drug addiction

28. Religious fanaticism and terrorism - secret cultism

29. Male teacher flogging female students on the exposed buttocks

30. Going home before the normal closing hour

31. Falsification of accounts

32. Forging of transfer certificates or results of students

33. Compelling students to buy books/handouts

34. Writing project/assignments for students in exchange for money

35. Victimizing students for sex, ethnics, religious or personal reasons

36. Offering money, sex or other enticement in exchange or higher grades or alteration/forgery of records/documents

37. Disobedience to copyright laws and photocopying of textbooks without permission from authors/publishers.

None of the ethical problems listed above needs to be taken for granted since its persistence can have a far reaching consequences on education policy implementation.

\section{Solution Toward Building Trust}

Cooper and Hingley (1985) observed that in some countries top management of some companies do not always tell people the fact, that they do quite appreciate the importance of developing closer working relationship with workers and open communication because of lack of trust. Such anomalies can be very dangerous in a school organization where quality management and trust among staff and principals are seen to be highly related. Many variables for quality management are related with ethical behavior. For instance, as Goetsch and Davis (2000) notes,

In human communication, receivers do not accept messages from senders they do not trust. In interpersonal relations, trust is most fundamental element. People who trust each other will be able to get along and work well together even in the worst of circumstances. On the other hand, people who do not trust each other will not be able to get along and work well together even in the best of circumstances. Trust is also a critical element in conflict management. A manager who is not trusted by both sides in human conflict cannot help resolve 
the conflict. For people to put aside their personal agenda and work together as a team, they must trust each other. If even one team member is concerned that another member is promoting his own self-interest over those of the team, teamwork will not succeed. Manager will not involve and empower employees unless they trust them. Involving employees and giving them a real voice in decisions that affect them is a demonstration of trust (p.107)

Since trust is so important for implementation of quality administration and quality education, the principal must establish himself as trustworthy, and also, must be essentially trust builder in the organization and among its employees. When the principal is successful in building trust among this staff, these noble values, being contagious will trickle down on the students for whom they are models. Studies by Bronfenbrener (1970) and Bandura (1977), cited in Jones and Jones (2004) uphold this assumption namely, that "individuals are more likely to model the behavior of people whom they view as possessing competence and control over resources and who are major source of control, support, and reinforcement"(p.51)

Goestsch and Davies (2000) indicate that one way principals can help build trust is to be loyal to those who are not present (say in a meeting). When a principal speaks up for someone who is not present but is being questioned or attacked, the employees get two simultaneous messages, namely that,

- Talking behind a colleague's back is not an acceptable behavior

- If this principal does not let me talk about fellow employees who are absent, he or she won't let others talk about me when I am absent.

Principals are human beings and sometimes make mistakes or do things or make utterances that can hurt employees. A sincere apology can build trust. Making excuses, pointing finger at or shifting blame to someone else, or ignoring the situation only exacerbates it. By simply and sincerely saying "this is my faulty, I am sorry" principals can build trust.

Keeping promises is another way principals can build trust. Dependability builds trust. Promises in the work place often take the form of deadlines. A deadline promised should be a deadline kept. Regardless of the promises made, the principal and the staff should keep them and expect others to do the same. It is easier to trust people who are dependable, even when one does not agree with them, than it is to trust someone who is not dependable. This means that for a principal to be able to build trust he must be a person of his word. The principal can build trust and respect by giving his subordinators reasons for the requests he makes or the directions he gives.

All these means that in any attempt to build trust in the workplace the principal should take the initiative even though trust building and other tasks necessary for organizational success are the responsibility of everyone. The principal should not sit back and expect trust building to come by God's Grace. His role is to get things moving and to stir the pot as necessary to keep things moving.

\section{Solution that Best fit the School Value System}

Values are principles of conduct such as caring, honesty, keeping of promises, pursuit of excellence, loyalty, fairness, integrity, respect for others, and responsible citizenship (Bateman $\&$ Snell, 1999). It is more elaborately defined as:

Those deeply held beliefs that form the very core of who we are. A person's conscience or internal barometer is based on his values. Our values guide our behavior. This statement also applies to organizations. An organization will not produce a quality product or provide quality service unless the organization values quality. Knowledge and skills are important, but by themselves they do not guarantee results. The individual employees and organizations as a whole 
will most willingly apply their knowledge and skills to what they value, what they believe (Goetsch \& Davis, 2000:107)

Other examples of values that are shared with others are; courage and courtesy; decency and tolerance; hardwork and service to others, civility and generosity. Core values such as these strongly influence our behavior and help us to distinguish between what is right and what is wrong. They also enable us stay the course and make hard decision even at the risk of rejection by our peers, and thus enhances stability (Siropolis, 1997).

In stressing the role of values in organizational survival, stability and excellence, Peters and Waterman (1982) point out that:

- In order to survive and succeed, an organization must have a set of beliefs on which it premises all its policies and actions.

- The most important single actors is corporate successes is faithful adherence to moral beliefs.

- If an organization is to meet the challenges of a changing world, it must be prepared to change everything about itself except those beliefs, as it moves through corporate life.

- How strongly people in the organization believe in its basic precepts and how faithfully they carry them out are vital for the organisation's survival and excellence.

Studies (Fenske \& Hughes, 1989) indicate that student values have been changing cyclically since the 1950s. The main characteristics: materialism; monetary and selfish goals; me first attitude and developing a philosophy of life. These studies also indicate that the "me generation attitude" which emerged by the (1980s) has persisted and intensified. The high wave of indiscipline, dishonesty and injustices that characterise the Nigerian educational system (Mni, 2008) is therefore not surprising.

Nigeria's schools therefore have the responsibility to promote, protect and transmit values of high ethics, peak performance and excellence in the students. Values that lead to these include fairness, dependability, integrity, honesty, truthfulness, achievement, contribution, self development, creativity, synergy, quality and opportunity. A school can foster excellent value system by promoting the beliefs in being the best performing school in the land; the best in sports and games; the cleanest school; the most disciplined, the most peaceful; the best in internal and external examination conduct; the most committed to students and public service, the best innovative and entrepreneurial - its graduates can craft self-help jobs and have "can do spirit; the best student and staff caring institution in the world, and the best to produce graduates that are admitted to universities.

Students, staff, parents and the community should be helped to imbibe these beliefs and expectations about the school. Behavior management principles of rational-emotive therapy demonstrate that, students' behavior, and by extension the school's, can be change by helping them make positive, thoughtful internalized statements in place of the negative unproductive statement they often make (Jones and Jones, 2004).

The principal's roles and value orientation in the organization are of three kinds: he is responsible for setting examples of the appropriate behavior; he is responsible for helping the students and teachers to take the right choices; he is responsible for helping them follow through and exhibit the appropriate behavior after the choice has been made. He can instill values through scores of daily events, not necessarily by charismatic personality but by obvious, sincere, sustained personal commitment to the values he seeks to implant, coupled with his extraordinary persistence in reinforcing these values (Peters and Waterman, 1997).

The principal can detect, promote and transmit values through such soft means as stories, myth, legends and metaphors; and through annual reports and other publications which make clear what the school is proud of and what its values are (Adesina, 1990). A very good 
opportunity for airing out the school values are the sports (inter- house sports) celebration and prize giving days when the principal is opportuned to address large publics.

Much of the principal's efforts in value transmission and promotion should be informal, especially through what Peters and Waterman (1977:289) call "management by wandering around" or "visible management". This makes him accessible and approachable to all stakeholders of the school. He should be like an evangelist, constantly in touch with the territory preaching the "truth" and listening to criticisms, suggestions as well as reasoning with people on the critical values of the school.

The principal should lead the school to be an exemplary good corporate citizen. According to Thompson and Strickland (2000) many managers of excellent American corporate organizations achieve this not only by seeing that their companies operate ethically, but that they also display a social conscience in decisions, that affect stakeholder, especially employees, the communities in which they operate, and the society at large. Taking active role in community affairs, being general supporters of charitable causes and projects that benefit society are some ways to demonstration this. They promote voluntarism, by involving the organizations and the employees in works to help alleviate social plights as strategies to develop the morale of workers.

Self reported experiences of students involved in community service and service learning projects conducted by Pennsylvania and South Carolina Universities, cited in Igwe and Nwikina (2005) confirm these. Volunteer or community service work helps in students self exploration, self understanding and love of the other people from different backgrounds. It makes them to be sound, good and responsible, and builds in them leadership skill, honesty and good citizenship values. More, it popularizes the institutions and makes them good corporate citizens.

\section{Solutions to Enhance School Organisational Integrity}

Integrity is another aspect of ethical behavior. Integrity, as a personal and organisational characteristics, combines honesty and dependability. When an individual or an organization has integrity, ethical behavior automatically follows. A reputation for integrity is earned only through doing what has been agreed to do, doing it on time, and with completeness. The Rivers State Government (RSG, 2009) is very apt in its definition and statement on the importance of integrity. It says:

Integrity is soundness of moral principle and character. It is the hallmark of all true manhood, wholeness and well being. The man who resolves early in life that, regardless of circumstances, he will promptly meet every obligation that he makes and makes character is chief success capital, places himself in the most favourable position for life race. There is no substitute for honesty and there are no success without it. Enduring success depends upon one's integrity - when character is, sacrificed we lost all. More lives have been destroyed by suicide of character than by disease or wars (p.9)

This applies not only to individuals but also to organizations that make integrity their hallmark. Zietlow (2004:123) writes that integrity is the foundation of organisation's accountability and stewardship. According to him "integrity means: (1) steadfast adherence to a strict moral or ethical code; (2) the state of being unimpaired, soundness; (3) the quality or condition of being whole or undivided, completeness - Organisations that possess integrity are managed in a sound manner, including fair and honorable treatment of donors, clients, students and employees. Also, there is a whole or undivided pursuit of the mission of the organisation, with employees self-interest kept secondary." 
There is the belief that integrity is more than just honesty though they are all important values for efficient and effective management. Honesty is mostly not doing things that are dishonest and more or less expected of respected people. People with integrity though can be counted thoroughly and completely, complete work on time, and keep promises. The same is also true of organization.

As regards promotion of integrity in the organization, Peter Drucker, cited in Goetsch and Davis (2000:115) opines

"No professional, be he doctor, lawyer or manager, can promise that he will indeed do good for his client. All he can do is try. But he can promise that he will not knowingly do harm. And the client, in turn, must be able to trust the professional not knowingly do harm to him. Otherwise he cannot trust him at all - the basic rule of professional ethic".

The school principals need to follow this rule, keep the best interest of the school, staff, students and parents in mind when taking decisions and in all aspects of their jobs. Committing to not knowingly do harm to any stakeholder, the school, or the public at large forces principals to think about the consequences of their action, before taken them. This rule also applies to employees, students and the organisation as a whole.

\section{Solutions for Promoting Responsibility}

Schools are subsets of the general society of ours where people do shun responsibility. People often blame others for their own shortcomings, and failures. People focus on rights but ignore the responsibilities that must accompany right. Passing blames has become common place. Employees often refer to their employers as "they" rather than" we" thus shifting blames for failures or errors from themselves to an unseen "they".

As Igwe (2003) observes, students, teachers, principals, parents, the schools Board and ministry of education, the community/society and the external examination conductors are often blaming each other for what they perceive as educational failure, especially for students' or schools' poor performance in external examinations and for the occurrence of examination malpractice. Intransigence, stonewalling, and "everyone-else -does it self-defence" and finger-pointing and not admitting wrongdoing, are common unethical behaviors in Nigeria education. To implement efficient and effective education however, people must be responsible for their action or inaction and be accountable for their performance. Bateman and Snell (1999) note that honesty and fairness - including admitting mistakes; apologizing genuinely, quickly, and sincerely; and making up for mistakes may pay dividends to conscience, to personal reputation, to the public image of the organization and to market response.

Accepting responsibility help build trust, integrity and all the other elements of ethics that are important for achieving quality education. Ethical behavior is not just something that is to be adhered to for the sake of being nice. In the long run, it is also the profitable thing to do. Failing to accept responsibility can be a formula for failure. The principal should take lead in demonstrating this ethical behavior and encourage his staff and students to emulate. Everyone in the school should accept the principle of the saints: "In showing honour - take the lead".

\section{Enshrining Ethical Culture in the School}

A strong corporate culture founded on ethical and moral values is sine qua non for continued education success. Stueart and Moran (2002) note that organisations that are well respected and profitable are almost always marked by good ethical cultural practices. Boone and Kurtz (1992) define corporate culture as "Generally accepted behavior pattern within an organization 
that are adopted by each new generation of employees. A corporate culture deals with an organisation's traditions and basic values. Many of these attributes are expressed in corporate slogans". Since ethical behavior most likely results from values held by the organisation's leaders combined with systems that promote ethical behavior, principals must be convinced that they are caring about how they operate the schools' businesses, otherwise theirs and the schools' reputation, and ultimately their performance and job are put at risk. Morally upstanding values and high ethical standards nurture the corporate culture in a positive - They connote integrity, doing the right thing, and genuine concern for stakeholders. Principals therefore need to create an environment of strongly held values and conviction to make ethical conduct a sustained way of life.

In building school ethical culture, school managers may learn many things from profit organizations. Thompson and Strickland (1998) note that:

In companies that strive hard to make high ethical and moral standards a reality, top management communicate its commitment in a code of ethics, in speeches and company publications, in policies and the consequences of unethical behaviours in the deeds of senior executives, and in the actions taken to ensure compliance. Senior management repeatedly tell employees that it is not only their duty to observe ethical code but also to report ethical violations. While such companies have provisions for disciplining violators, the main purpose of enforcement is to encourage compliance rather than administer punishment. Although the CEO leads the enforcement process, all managers are expected to make a personal contribution by stressing ethical conduct with the subordinates and monitoring compliance with the code (pp.355-356).

This means that companies establish values and ethical standards, beside other strategies, principally by:

- Relying on word of mouth indoctrination and power of tradition to instill values and enforce ethical standards;

- Setting forth their values and code of ethics in written documents.

Further, it means, that it is not enough to assume activities are being conducted ethically, nor can it be assumed that employees understand they are expected to act with integrity.

The written code or statements have many advantages including the following:

- Explicit statements of the organisation's intents and expects

- Benchmarks for judging organisation's policies, actions and individual conduct.

- Put a stake in the ground and define the organisation's position.

- Serve as cornerstone for culture building

- Serve as cornerstone for developing a corporate conscience

- Becomes a unifying force for the organization

Many codes of ethics have been developed by professional bodies, institutions and other facilities in education in Nigeria, by which principals and schools can be guided and which can be translated for their use. For instance, the Teachers Registration Council of Nigeria (TRCN 2004) provides a code of conduct for teachers and students. There is also Examination ethics drawn at the 1986 National Conference on Examination project, held at Ota in Ogun State, Nigeria. This emphasizes on honesty, integrity, and dignity in study and good citizenship as values necessary for prevention of examination malpractice among students (Mni, 2008).

Many universities have also drawn a code of conduct and ethics. As the University of Port Harcourt Code states, the purpose is to "Ensure that the behavior and actions of staff and 
students of the University are guided by high ethical standards anchored on the core values of honesty, integrity, fairness, justice, impartiality, loyalty and faithfulness".

Implementing the values and code of ethics in school organization according to Thompson and Strickland would entail the following actions:

- Incorporating the statement into employees training and educational programmes.

- Explicit attention to values and ethics in recruiting and hiring or screening out applicants who lack compatible character traits.

- Communication of values and ethic code to all employees and explaining compliance procedures.

- Management involvement and oversight, from the principal to students.

- Strong leadership commitment and endorsement

- Word-of-mouth indoctrination

Further, special attention must be given to sections of the school businesses that are particularly sensitive and vulnerable, such as examination, finance, and female rights. Also, procedures for enforcing ethical standards and handling potential violations have to be developed.

The compliance effort must permeate the entire school extending to all its units. The departmental heads, supervisors of academic, administrative and technical units must give serious and continuous attention to the task of explaining how values and ethical code applies in their areas. In addition they must insist that the school values and ethical standards become a way of life. Managing ethically is not easy, but it is the responsibility of all the managers to uphold high ethical cultural standard within their organisations (Stueart \& Moran, 2002).

It should be noted that, the principal can do several concrete things to exercise ethics leadership: He should demonstrate the importance of ethics by his own behavior, should be certain that appropriate codes of behavior are in place and that employees (teacher and students) are well informed of them, and should monitor the behavior of employees to be sure they are complying. Specifically, he and his senior staff members should take the following leadership responsibilities:

1. They must set an excellent ethical example in their own behavior and establish a tradition of integrity. The school decisions have to be seen as ethical- "actions speaks louder than words".

2. Principal, staff and students have to be educated about what is ethical and what is not; ethical training programmes have to be established and gray areas pointed out and discussed.

Everyone must be encouraged to raise issues with ethical dimensions, and such discussions should be treated as legitimate topic.

3. Top management (principal and senior staff) should regularly restate its clear support of the school's ethical code and take a strong stand on ethical issues.

4. They must reprimand those who have been lax in monitoring and enforcing ethical compliance.

5. They must be prepared to act as final arbiter in hard calls - removal or recommending removal of people from key position or terminating them when they are guilty of a violation.

Failure to act swiftly in punishing ethical misconduct is interpreted as lack of real commitment. This is why the University of Port Harcourt is very stringent on this policy. It states categorically that: "Non-compliance with (its) code of conduct by any staff or student will attract appropriate sanction" (Uniport Code of Conduct).

\section{Conclusion and Recommendations}

Various elements of quality and excellent school management such as communication, interpersonal relations, conflict management, problem solving, team work, employees involvement and empowerment are dependent on attainment of ethical and moral values of the 
stakeholders of the school especially principal, staff and students. The purpose of the National Policy on Education cannot be achieved unless there is a success of ethical and value orientation efforts of schools. School managers should therefore be involved in efforts to build trust, promote value of integrity and responsibility; and to build, sustain, corporate culture of high ethics and values.

These ethics and relevant moral values can be transmitted, promoted, protected as the school corporate culture by words of mouth indoctrination and power of tradition, and by setting forth a code of ethics and values in written document. The code then becomes a cornerstone for cultural building and for developing a corporate conscience as well as a unifying force for the school. It also becomes a benchmark for judging the schools policies, actions and individual conducts.

Schools should implement values and code of ethics by: incorporating the statement into employees' training and educational programmes; giving explicit attention to values and ethics in recruiting and hiring or screening out applicants who lack compatible character traits; communication of values and ethics code to all employees and explaining compliance procedures; and importantly strong leadership commitment and endorsement of excellent ethical examples in their own behavior. Principal must be able to reprimand those who have been lax in monitoring and enforcing ethical compliance and must not hesitate to remove, recommend removal of people who are guilty of a violation.

\section{References}

Adesina, S. (1990) Educational management. Enugu: Fourth Dimension Publishing Co. Ltd

Amirize, B. (2005)

Bateman, TS \& Snell, S.A. (1999) Management: building competitive advantage. Boston: McGraw-Hill

Cooper, C.L. \& Hingley, P. (1985) The change makers. London: Harper \& Row Publishers.

Fayoku, K.O. \& Adedeji, S.O. (2008) Legal issues in educational management in Nigeria. In J.B. Babalola; A.O. Ayeni; S.O. Adedeji; A.A. Suleiman; M.O.A. Arikewuyo (eds) Educational management: thoughts and practice pp.320-354. Ibadan: Codat publications

Federal Republic of Nigeria (2004) National Policy on Education. Federal Government Printers, Abuja.

Federal Republic of Nigeria (2002) TRCN Handbook. Abuja: Teachers Registration Council of Nigeria.

Goestsch, D.C \& Davis (2002) Quality management. Columbus: Prentice Hall.

Igwe, L.E.B \& Nwikina, L. (2005) Concepts, principles, policies and practices of community service: implications for effective school administration. Port Harcourt: Caldwel Nigeria Ltd.

Igwe, L.E.B (2003) Elements of education law. Port Harcourt: Pam Unique Coy. Ltd.

Jone, V. \& Jones, L. (2004) Comprehensive classroom management. Boston: Allyn and Bacon. 
Kuh, G.D (1989) Organisational concepts and influences. In U. Delworth; G.R. Hanson (eds) Students services: a handbook for the professional; pp.209-242, San Francisco: Jossey-Bass Publishers

Mni, I.B. (2008) Value orientation of Nigerians: implications for quality assurance in public examinations. In Journal of the Nigerian academy of education (JONAED) 411.

Peters, T.J. \& Waterman, R.H. (1982) In search of excellence: lessons from America's best-run companies. New York: Harper and Row Publishers

Rivers State Government (2009) Doing government business in Rivers state: a code of ethics for public officers and civil servants. Port Harcourt: Ministry of Information

Sikropodi, N. (1997) Small business management. New York: Houghton Mifflin Company

Stueart, R.D \& Moran, B.B (2002). Library and information center management. Colorado: Libraries Unlimited/Greenwood Publishing

Thompson, A.A. \& Strickland, A.J. (1998) Strategic management. Boston: McGraw-Hill

University of Port Harcourt (ud) Code of conduct for staff and students Uniport: Professional ethics committee

Zietlow, J. (2000) Developing financial accountability and control. In Queen II, E.L (ed) Serving those in need. Sand Francis: Jossey-Bass. 